\title{
A DUPLA MEDIAÇÃO NO JOGO DE PAPÉIS: DO SIGNO E DO PROFESSOR PRÉ- ESCOLAR COMO PORTADOR DA SIGNIFICAÇÃO
}

\author{
Silvio Sena, Célia Maria Guimarães \\ Universidade Estadual Paulista - UNESP, Presidente Prudente, SP. E-mail: silvio seduc@presidenteprudente.sp.gov.br
}

\begin{abstract}
RESUMO
Este trabalho deriva da pesquisa de Doutorado intitulada $A$ dialética entre a intervenção pedagógica no jogo de papéis e o desenvolvimento da criança pré-escolar. Objetiva assinalar contribuições da mediação pedagógica no jogo de papéis e suas implicações para o desenvolvimento da criança pré-escolar. Como sujeitos, elege vinte crianças de uma turma de pré Il de uma escola da rede pública de Presidente Prudente. A metodologia, quali-quantitativa, se caracteriza como pesquisa-intervenção. Ainda que parciais, os resultados sublinham avanços do brincar infantil em direção à realidade objetiva, relacionados ao caráter das ações, à utilização de objetos substitutos, à adoção de papéis complementares e às relações estabelecidas entre coetâneos. Como resultado, almeja contribuir no campo teórico-metodológico na formação inicial e continuada dos professores pré-escolares, apontando caminhos e formas de intervir no jogo de papéis sem descaracterizar esse fenômeno, de sorte a cooperar para o avanço qualitativo dessa etapa da Educação Básica.
\end{abstract}

Palavras-chave: Jogo de papéis. Criança. Professor Pré-Escolar. Mediação. Desenvolvimento.

\section{A DOUBLE MEDIATION IN THE ROLE PLAY: THE SIGN AND THE PRESCHOOL TEACHER DOUBLE MEDIATION IN THE ROLE PLAY AS SIGNIFICANCE CARRIER.}

\begin{abstract}
This work stems from PhD research titled The dialectic between the pedagogical intervention in the role play and the preschool child development. It aims to point pedagogical mediation contributions in the role play and its implications for the preschool child development. As subjects, it is elected twenty children in a preschool class in a public school in a public school in the city of Presidente Prudente (São Paulo state). The quali-quantitative methodology is characterized as intervention research. Although partial, the results highlight the advances children make through the play toward the objective reality, related to the character of actions, the use of substitute objects, the adoption of complementary roles and relations established between peers. As a result, it aims to contribute to the theoretical and methodological field in initial and continuing training of preschool teachers, pointing paths and ways to interven in the role play without spoiling this phenomenon, so as to cooperate for the qualitative advance of this Basic Education stage.

Keywords: Role play. Child. Preschool teacher. Mediation. Development
\end{abstract}




\section{INTRODUÇÃO}

Este artigo eflui da pesquisa de Doutorado denominada $A$ dialética entre a intervenção pedagógica no jogo de papéis e o desenvolvimento da criança pré-escolar, que, por sua vez, brotou da ampliação e aprofundamento de nossa Dissertação de Mestrado, intitulada $O$ jogo como precursor de valores no contexto escolar. Tal trabalho, defendido em novembro de 2007, investigou, no contexto escolar de crianças dos anos iniciais do ensino fundamental, por meio de pesquisa-intervenção, a incorporação, através do jogo de movimento (regras), dos valores respeito mútuo, cooperação, solidariedade e perseverança.

Após a conclusão desse trabalho, instalou-se a inquietação gerada pela intenção de ampliar e aprofundar questões ali emergidas, associadas às possibilidades e limites da brincadeira-jogo como conteúdo e recurso pedagógico, no contexto educacional. Em razão do incômodo, iniciamos um intenso movimento de busca de elementos que pudessem significar e respaldar, em nível de doutoramento, as alternativas envoltas na consideração desse fenômeno como objeto de pesquisa.

Em acordo com o referencial teórico desta pesquisa, isto é, com o enfoque Histórico-Cultural composto pela Psicologia Histórico-Cultural e a Pedagogia HistóricoCrítica como unidade teórico-metodológica, conclui-se que a educação não sucede apenas nas instituições de ensino, mas também nas famílias, nos clubes, nas igrejas e em todos os demais espaços, nos quais ocorrem processos interativos do indivíduo com outros membros do gênero humano e com artefatos historicamente produzidos pela humanidade.

Posta-se assim, na ótica destacada, evidente que a cultura popular ocupa uma posição de extrema relevância no processo de humanização (desenvolvimento), no entanto, sabe-se também que a transmissão (ensino) dos saberes populares não se configura como papel específico da escola, pois o indivíduo pode se apropriar deles em outros espaços da convivência humana. A natureza do saber a ser transmitido no espaço escolar não se confunde com aquele que pode ser igualmente apreendido nos demais espaços de interação, Inclusive, pode-se afirmar que o sentido da criação da escola se traduz na função específica da transmissão do saber da ciência.

Segundo a Psicologia HistóricoCultural, a gênese da brincadeira é social e seu principal atributo se consubstancia em sua função humanizante. Brincando, a criança aprende como falam, pensam, agem e sentem as pessoas de seu grupo cultural, tornando-se, assim, uma delas. Para tanto, ela se apoia em sua realidade social, 
extraindo dela, através da memória de suas vivências de outrora, as regras que delineiam as formas socialmente estabelecidas de operar os objetos humanos e realizar as ações/funções humanas com eles. Nesse processo, por meio da imitação diferida, dialeticamente, a criança exercita, reitera e assimila as regras e habilidades sociais, efetuando, por operações com objetos significados e significantes, transformações no plano simbólico, de sorte a ressignificar e superar as limitações impostas pela realidade objetiva.

Partindo do pressuposto de que a Psicologia Histórico-Cultural posiciona o jogo de papéis como atividade principal da criança pré-escolar, percebida como aquela “[...] cujo desenvolvimento governa as mudanças mais importantes nos processos psíquicos e nos traços psicológicos da personalidade da criança [...]" (LEONTIEV, 2012, p. 65), e que os documentos oficiais fixam as brincadeiras e as interações como atividades eixo da Educação Infantil, decidimos realizar o levantamento de trabalhos acadêmicos que acolheram a brincadeira como objeto especifico de investigação cientifica.

A partir dos descritores de busca $O$ brincar na educação infantil, o jogo na educação infantil, o jogo de papéis na educação pré-escolar, o brincar da criança pré-escolar e a brincadeira na educação infantil, procurou-se, no banco de periódicos
Qualis CAPES A1, A2, B1, B2, de dissertações e teses da UNESP, USP, UNICAMP e nos arquivos da Associação Nacional de PósGraduação e Pesquisa em Educação (ANPED), trabalhos publicados de 2009 a 2012. O levantamento totalizou trinta e um textos que fazem referência ao jogo de papéis como objeto de pesquisa, doze artigos de periódicos, dez dissertações, duas teses e sete trabalhos da ANPED.

Os trabalhos encontrados fazem uso de instrumentos de coleta de dados como observação participante, questionários/entrevistas estruturados e semiestruturados, fotografias, filmagens e registros escritos em caderno de campo. Dividem-se em pesquisas caracterizadas como etnográficas, nas quais a mediação do professor se limita à organização prévia dos espaços e materiais (brinquedos) e à análise do brincar extraída de registros de observações do brincar infantil; documentais, por meio das quais se investigou o direito da criança de brincar, a concepção de educadores da Educação Infantil sobre o jogo de papéis e a utilização desse fenômeno como instrumento didático, no contexto educacional; e pesquisas-intervenção, nas quais o objeto da intervenção é a formação didático-pedagógica de estagiários, educadores e professores da Educação Infantil. 
Como se observa, inexistem, no citado período, trabalhos nos quais o problema específico de pesquisa seja a intervenção pedagógica do professor no brincar infantil, sem descaracterizar esse fenômeno e considerando os benefícios que o elevam ao status de atividade principal da criança na fase pré-escolar.

Desse exposto, este trabalho organiza e apresenta a análise parcial de alguns dos elementos que compõem a totalidade da pesquisa da qual se origina. Prevê formas particulares de participação do professor, no entanto, sempre sob o crivo da intencionalidade, fixando os seguintes objetivos: 10 - Intervir e mensurar, a partir das premissas que constituem o jogo de papéis (caráter das ações, utilização de objetos substitutos, adoção de um papel e relação com coetâneos), o nível de jogo praticado pelas crianças; 20 - Estabelecer, de maneira dialética e integrada, a correlação entre o avanço do nível de jogo praticado pela criança e os elementos que medeiam, conformam e estruturam o processo de humanização (desenvolvimento) da criança pré-escolar, na perspectiva do Enfoque Histórico-Cultural, a saber: o biológico, o social, o histórico, o cultural e a atividade.

\section{METODOLOGIA}

Com procedimentos qualiquantitativos, a investigação se efetiva com crianças pré-escolares a partir das implicações da mediação/intervenção pedagógica no jogo de papéis e do respectivo progresso, ou não, do nível do brincar observado.

A pesquisa se configura como uma das modalidades de pesquisa-ação; "[...] a pesquisa-ação não é considerada como metodologia. Trata-se de um método, ou de uma estratégia de pesquisa agregando vários métodos ou técnicas de pesquisa social, com os quais se estabelece uma estrutura coletiva, participativa e ativa ao nível da captação de informação" (THIOLLENT, 2008, p. 28). A metodologia se caracteriza como pesquisa-intervenção, na qual a relação pesquisador/objeto pesquisado é dinâmica e determinará os próprios caminhos da pesquisa, sendo uma produção do grupo envolvido (AGUIAR; ROCHA, 1997).

No que concerne à faixa etária e etapa escolar, participam vinte crianças de uma turma do Pré II da Educação Infantil (quatro anos) da escola selecionada para o desenvolvimento da investigação.

A mediação/intervenção sucede em dois momentos: o primeiro, marcado pela roda de conversa, e o segundo, assinalado pelo processo do brincar. A roda de conversa cumpre a finalidade de enriquecer as representações individuais, compartilhando as experiências pessoais e pontos de vista, entre todos; é o momento para eleger os 
temas, argumentar, debater e demonstrar as formas e meios pelos quais os personagens genéricos operam os objetos culturais e realizam as ações humanas com eles. 0 momento do brincar visa a enriquecer o jogo de papéis, sugerindo a adoção de objetos substitutos e a inclusão de personagens complementares.

Sob a base dos pressupostos do Enfoque Histórico-Cultural, elege-se o nível de atuação da criança e seu avanço, no jogo de papéis, como objeto central de análise, ou seja, como variável dependente. Com a observação participante, outorga-se à intervenção pedagógica, no jogo de papéis, o status de principal recurso pedagógico; em outras palavras, a intervenção pedagógica funciona como variável independente.

A coleta de dados se dá através de registros escritos, fotografias e filmagens. A permissão para utilização das imagens incididas das crianças defere do Parecer Consubstanciado do Comitê de Ética em Pesquisa (CEP) de 09/05/2014, no 644.590, emitido pela Universidade Estadual Paulista FCT/UNESP, Câmpus de Presidente Prudente. Convém enfatizar que tais recursos se postam como meios para que seja possível a retomada contextual e interpretativa das situações advindas do jogo de papéis.

As categorias de análise se consubstanciam nas premissas constitutivas do jogo de papéis estabelecidas por Elkonin
(1998), identificadas como caráter das ações, utilização de objetos substitutos, adoção de um papel e relação entre coetâneos. Destaque-se que o aspecto central, que agrupa todos os demais, é o papel assumido pela criança.

A análise dos dados se efetiva com o cuidado em assegurar coerência entre o método e a posição teórica adotada. Valemonos da ideia de William Corsaro, de forma a alternar a observação empírica com a observação interpretativa obtida pela inserção de observação participante, de registros cursivos e imagens (fotografias e filmagens) em contextos holísticos (ADES, 2009).

A implementação total do trabalho empírico se completou em dezembro de 2014. Sucedeu como prevista, isto é, de acordo com a organização e possibilidades da professora regular, no interstício compreendido entre julho a dezembro, com, no mínimo, uma, e no máximo, duas sessões semanais, cada qual de $01 \mathrm{~h} 00 \mathrm{~min}$. 0 trabalho de campo se compôs das fases sondagem de constatação diagnóstica inicial, ocorrida nas quatro primeiras semanas - 6 sessões; intervenção, principiada a partir da quinta semana - 15 sessões; e sondagem de constatação diagnóstica conclusiva, a qual permeou as últimas três semanas -5 sessões. Por principal finalidade, a fase derradeira vislumbrou constatar, em caráter conclusivo, 
o progresso, ou não, das crianças em relação ao jogo de papéis e aos respectivos processos de desenvolvimento. Na totalidade do trabalho, somaram-se 26 sessões.

\section{RESULTADOS}

Sob a égide da dupla mediação, isto é, do signo e dos professores como portadores da significação, ainda que parciais, os resultados apontam e acentuam progressos no nível de mediação/intervenção, no jogo de papéis, e no desenvolvimento das crianças, relacionado às categorias de análise.

Perante a exigência de este artigo se enquadrar no limite máximo de oito páginas, na tentativa de descrever o processo, ilustraremos apenas os episódios aflorados na sessão oito da fase experimental, de sorte a buscar explicitar a dialética latente no processo duplo de mediação com respeito às categorias caráter das ações, utilização de objetos substitutos, adoção de um papel e relação com coetâneos.

\section{DISCUSSÃO}

Diferente da estratégia tomada nas sessões precedentes, para aquela, os professores combinaram iniciar com as brincadeiras de livre escolha, sendo que tanto o professor-pesquisador como a professora-regular participariam como brincantes e por meio de demonstrações práticas direcionadas a adoção de papéis centrais e sugestão de personagens complementares e de objetos substitutos.

O número de crianças contabilizadas somou dezoito ${ }^{1}$. Após as crianças escolherem os brinquedos e dividirem o espaço da sala de aula para a implementação do brincar, verificou-se o seguinte episódio: os alunos NM e LM estavam brincando de caçadores, cada qual empunhando uma espada de brinquedo e simulando duelar com elas, quando o caçador NM atingiu o adversário (LM) com sua espada, que veio a cair ferido. Aproveitando a situação, o professorpesquisador imediatamente se apresentou como médico e se propôs tratar do caçador ferido. Para tanto, solicitou das crianças que pegassem um pincel atômico que se encontrava à vista, para se tornar o seu termômetro. Ao lhe ser entregue o objeto, executou as ações inerentes à aferição da temperatura corporal. Em seguida, pegou um lápis que se encontrava sobre uma das carteiras, e disse às crianças que ali se encontravam: "Esta é minha injeção!". Simulou aplicar a injeção no caçador ferido e, pela utilização de um estetoscópio de brinquedo, representou a ação médica de auscultar o coração do enfermo. Após essa

\footnotetext{
${ }^{1}$ Neste trabalho, primeiramente, as crianças são identificadas por duas iniciais: a primeira se refere ao primeiro nome (J de José Eduardo, por exemplo) e a segunda, ao gênero do qual faz parte ( $F$ de feminino e $M$ de masculino). Nesse caso, José Eduardo seria identificado como JM. Quando a inicial do primeiro nome é comum a mais de uma criança, utilizamos as duas primeiras para identificar a pessoa e a terceira para o gênero. Em tal situação, José Eduardo seria mencionado como JEM.
} 
sequência de ações, disse: "As batidas do coração estão boas!" Nisso, o caçador ferido recuperou seus sentidos e se levantou, afirmando já se encontrar curado e encerrando-se, assim, a brincadeira.

A demonstração prática das ações características do personagem genérico médico -, advinda do professor-pesquisador, influenciou muitas crianças a inserir esse personagem no brincar ali manifesto, acomodando-o na peculiaridade de cada situação lúdica. Cite-se o segundo episódio, emergido naquela sessão, no qual os professores foram convidados a participar do brincar de casinha pela criança EVF, que, na brincadeira, seria a mamãe, tendo como seu bebê uma boneca; MF seria a titia; EEF e DF seriam as filhinhas; e LF, a médica. O professor-pesquisador seria o papai, devendo fazer comida e se relacionar com os demais membros da família. Ao iniciar a trama, DF e EEF (filhinhas) deram um abraço no papai e disseram que iriam ao shopping, mas logo retornariam. Saíram e, em seguida, regressaram, abraçando o papai e dizendo: “Oi, papai, já voltamos!" O papai perguntou: "Foi tudo bem no passeio, vocês se divertiram bastante?" Prontamente, as filhinhas responderam que o passeio fora ótimo, que haviam comido batata recheada e passeado bastante.

Quando, ansiosa, EVF (mamãe) exclamou: "Meu bebê está doente, por favor, chamem um médico!" Imediatamente, a aluna LF assumiu as ações desse personagem, reproduzindo as ações de médico previamente representadas pelo professor-pesquisador. Ela fez uso de uma caneta para medir a temperatura, de um lápis para simbolizar e substituir a injeção real e de um estojo de lápis para desenvolver a ação de auscultar o coração do bebê enfermo (boneca). Além disso, inseriu dois novos elementos (objetos substitutos) na trama: pegou uma xícara e uma folha de papel avulsa; com o primeiro objeto, imitou as ações de dar remédio via oral para o bebê e, com o segundo, fingiu escrever, enfatizando que aquele era seu receituário e que estava escrevendo a receita médica. Em seguida, disse: “Mamãe, seu bebê já está bem, pegue esses remédios da receita no postinho!"

A descrição acima revela ações e pautas de comportamento do personagem médico, exemplificadas pelo professorpesquisador, as quais foram reproduzidas e qualitativamente superadas pela criança LF. Inseridas no exemplo, identificam-se as formas socialmente estabelecidas das ações características do médico, as criativas possibilidades da inserção de objetos substitutos e as relações sociais (profissionais) dialeticamente mobilizadas pelos papéis sociais acolhidos em ambos os episódios. 


\section{CONSIDERAÇÕES FINAIS}

Dos episódios supracitados,
depreendem-se implicações para o
desenvolvimento infantil emanadas pela
dupla mediação no jogo de papéis. Pode-se
inferir que a adequada mediação no brincar
infantil enriquece, diversifica e mobiliza, na
subjetividade infantil, as premissas
constituintes do jogo de papéis, as quais se
postam como categorias de análise da
pesquisa da qual deriva este trabalho.

De acordo com os resultados, podese afirmar que, quanto mais avançado for o nível de jogo praticado, mais a criança progride em seu desenvolvimento. Nesse processo, ela exercita o pensamento abstrato, ainda em fase embrionária, atuando como se fosse maior e mais desenvolvida do que de fato é, criando uma zona de desenvolvimento iminente, de modo a ampliar o conhecimento objetivo que tem do sistema de relações sociais do qual faz parte, humanizando-se por meio da apropriação cultural.

Enfim, a pesquisa aponta e grifa resultados que podem contribuir no campo teórico-metodológico da prática educativa do professor pré-escolar. Para tanto, indica caminhos e formas de mediar/intervir no jogo de papéis, sem descaracterizar esse fenômeno, de modo a fazer valer os atributos essenciais dessa forma de atividade, os quais podem respaldar novos estudos e pesquisas, com vistas a contribuir para com a formação inicial e continuada desse professor e com o avanço qualitativo do ensino nessa etapa da Educação Básica.

\section{REFERÊNCIAS}

ADES, C. Um adulto atípico na cultura das crianças. In: MÜLER, F.; CARVALHO, A. M. A. (Org.). Teoria e prática na pesquisa com crianças: diálogos com William Corsaro. São Paulo: Cortez, 2009.

AGUIAR, K. F.; ROCHA, M. L. Práticas universitárias e a formação sóciopolítica. Anuário do Laboratório de Subjetividade e Política, v.3, n. 4, p. 87-102, 1997.

ELKONIN, D. B. Psicologia do jogo. São Paulo: Martins Fontes, 1998.

LEONTIEV, A. N. Uma contribuição à teoria do desenvolvimento da psique infantil. In: VYGOTSKY, L. S.; ALEXANDER, R. L.; LEONTIEV, A. N. Linguagem, desenvolvimento e aprendizagem. São Paulo: Ícone, 2012.

THIOLLENT, M. Metodologia da pesquisaação. São Paulo: Cortez, 2008.

Recebido para publicação em 22/06/2015 Revisado em 29/06/2015 Aceito em 03/07/2015 